\title{
Emergency Medicine Journal
}

\section{Point-of-care testing with high sensitivity cardiac troponin assays: The challenges and opportunities}

\begin{tabular}{|r|l|}
\hline Journal: & Emergency Medicine Journal \\
\hline Manuscript ID & emermed-2021-211907.R2 \\
\hline Article Type: & Practice review \\
\hline Author: & n/a \\
\hline Complete List of Authors: & $\begin{array}{l}\text { Cullen, Louise; Royal Brisbane and Women's Hospital } \\
\text { Collinson, Paul O; St George's University of London } \\
\text { Giannitsis, Evangelos; University Hospital Heidelberg, Medical } \\
\text { Department III }\end{array}$ \\
\hline Keywords: & emergency department, assessment \\
\hline &
\end{tabular}

\section{SCHOLARONE \\ Manuscripts}


I, the Submitting Author has the right to grant and does grant on behalf of all authors of the Work (as defined in the below author licence), an exclusive licence and/or a non-exclusive licence for contributions from authors who are: i) UK Crown employees; ii) where BMJ has agreed a CC-BY licence shall apply, and/or iii) in accordance with the terms applicable for US Federal Government officers or employees acting as part of their official duties; on a worldwide, perpetual, irrevocable, royalty-free basis to BMJ Publishing Group Ltd ("BMJ") its licensees and where the relevant Journal is co-owned by BMJ to the co-owners of the Journal, to publish the Work in this journal and any other BMJ products and to exploit all rights, as set out in our licence.

The Submitting Author accepts and understands that any supply made under these terms is made by BMJ to the Submitting Author unless you are acting as an employee on behalf of your employer or a postgraduate student of an affiliated institution which is paying any applicable article publishing charge ("APC") for Open Access articles. Where the Submitting Author wishes to make the Work available on an Open Access basis (and intends to pay the relevant APC), the terms of reuse of such Open Access shall be governed by a Creative Commons licence - details of these licences and which Creative Commons licence will apply to this Work are set out in our licence referred to above.

Other than as permitted in any relevant BMJ Author's Self Archiving Policies, I confirm this Work has not been accepted for publication elsewhere, is not being considered for publication elsewhere and does not duplicate material already published. I confirm all authors consent to publication of this Work and authorise the granting of this licence. 
Point-of-care testing with high sensitivity cardiac troponin assays: The challenges and opportunities

Keywords: point-of-care, cardiac, troponin, assays 
Authors (in this order):

Professor Louise Cullen, MBBS(Hon), FACEM, Ph.D.

Clinical Researcher/Consultant

Emergency and Trauma Centre

Royal Brisbane and Women's Hospital

Cnr Butterfield St. and Bowen Bridge Road

HERSTON QLD 4029

Australia

Email: Cullen.|@outlook.com

Paul Collinson, MD

Professor of Cardiovascular Biomarkers

St. George's University of London

Cranmer Terrace

London, England SW17 ORE

United Kingdom

Email:paul.collinson@stgeorges.nhs.uk

Evangelos Giannitsis, MD

Assistant Professor, Cardiology

Medical Department III

University Hospital Heidelberg

Im Neuenheimer Feld 672, 69120

Germany

Email: evangelist.giannitsis@med.uni-heidelberg.de 


\begin{abstract}
Methods to improve the safety, accuracy, and efficiency of assessment of patients with suspected acute coronary symptoms have occupied decades of study and have supported significant changes in clinical practice. Much of the progress is reliant on results of laboratory-based high-sensitivity cardiac troponin assays that can detect low concentrations with high precision. Until recently, point-of-care (POC) platforms were unable to perform with similar analytical precision as laboratory-based assays, and recommendations for their use in accelerated assessment strategies for patients with suspected acute coronary syndrome has been limited. As POC assays can provide troponin results within 20 minutes, and can be used proximate to patient care, improvements in the efficiency of assessment of patients with suspected acute coronary syndrome is possible, particularly with new high-sensitivity assays.
\end{abstract}

This manuscript evaluates the POC testing cardiac troponin assays including new high-sensitivity assays, highlights current clinical assessment practices for patients with possible acute coronary syndromes, and forecasts future opportunities with use of such assays. 
1 The high burden of cardiovascular disease, and that of acute coronary syndromes (ACS) in particular,

2 within society has significant impact on patients, clinicians, and healthcare services. Symptoms of

3 chest pain, indicative of possible acute myocardial infarction (AMI), are one of the most common

4 causes for emergency department (ED) presentations worldwide, with suspected ACS patients

5 accounting for approximately $10 \%$ of all emergency visits. ${ }^{1}$ Decades of investigation into methods to

6 improve the safety, accuracy, and efficiency of assessment practices for patients with chest pain and

7 suspected ACS have supported significant change in clinical practice..$^{2,3}$

9 Many of the advances in clinical care are reliant on laboratory-based high-sensitivity cardiac troponin (cTn) assays ${ }^{3}$ with the greatest benefits realised in hospital-based care in large institutions. ${ }^{4}$ These cTn assays, used for the detection of myocardial injury, ${ }^{2}$ allow the detection of low concentrations with high precision. ${ }^{5}$ Point-of-care (POC) platforms are available, yet until recently the ability for this modality to perform with the accuracy and precision of laboratory-based cTn assays has been unattainable. ${ }^{6-9}$ This paper reviews the state of the art of POC cTn assays, highlights current clinical assessment practices for patients with possible ACS, and forecasts future opportunities with true high sensitivity POC assays.

\section{The role of troponin and use of troponin assays}

19 To understand the significant changes in this practice area, it is important to be aware of two key events that occurred following the introduction and subsequent development of cTn assays. First, the change from diagnosis using creatine kinase MB to $\mathrm{CTn}$ increased the risk of a biochemical falsepositive from $0.044 \%$ (classified as abnormal when more than twice the $97.5^{\mathrm{TH}}$ reference limit) to $1 \%$

23 (abnormal when above the $99^{\text {th }}$ percentile). ${ }^{10-12}$ The second is the improvement in troponin assays. 
sensitivity combined with the use of the $99^{\text {th }}$ percentile resulted in previously undiagnosed myocardial injury being detectable in a range of clinical conditions. ${ }^{2}$ Currently, high sensitivity troponin (hs-cTn) assays are in routine clinical use in many laboratories and are defined by two criteria. Firstly, the coefficient of variation (CV) at the $99^{\text {th }}$ percentile upper reference limit (URL) should be $\leq 10 \%$, and secondly that measurable concentrations should be attainable at a concentration at or above the assay's limit of detection (LoD) for $>50 \%$ of healthy individuals. ${ }^{13}$ Hence, hs-cTn assays represent the reference analytical standard against which diagnostic strategies must now be compared.

To date, in each clinical situation where troponin elevation has been detected and where MI or ACS is not suspected, the troponin elevation has been shown to be prognostic. More troponin is worse than less troponin and no troponin is better than any troponin. Troponin measurement remains an excellent rule-out test. Use of the term "troponinitis" is trivialising and clinically dangerous. ${ }^{14}$ Any elevated troponin requires explanation, yet not necessarily catheterisation or a cardiologist review.

Evidence for the clinical use of hs-cTn assays in patients presenting with chest pain has recently been reviewed and recommended for the early rule out of MI. ${ }^{3,15}$ Such assays have also been described within rapid predictive algorithms by the European Society of Cardiology ${ }^{3}$ and although data is included about POC hs-cTn assays, the recommendations at the time of writing are for use of laboratory-based assays. This is congruent with recommendations from the NICE Guidelines ${ }^{15}$ that suggest further evaluation of the performance of POC cTn assays using whole blood samples (rather than stored plasma samples) is required before clinical use. 
The performance characteristics of point-of-care test (POCT) troponin assays is summarised in table $1{ }^{16}$ including newer assays that reach the analytical classification of high-sensitivity assay. In addition to classification based on analytical performance, they can also be divided into compact desktop systems aimed solely at bedside use, and larger systems suitable for close to patient operation or use in an emergency testing facility. The analytical and clinical performance characteristics of these systems have been examined in independent evaluations. ${ }^{6-9,17,18}$ Evaluation has been using the same criteria as laboratory based assays to a predicate method of comparable analytical sensitivity. In addition, three new prototype systems have been documented that have the potential for clinical use. ${ }^{18-20}$

Most evaluations of POCT troponin assays have been based on the ability to achieve comparable diagnostic classification for MI in comparison with laboratory-based assays, with diagnosis based on being able to detect troponin above the $99^{\text {th }}$ percentile 3-6 hours from presentation. POCT assays meeting contemporary sensitive criteria are reliable for ruling in AMI on admission for samples exceeding the 99 th percentile ${ }^{9}$ yet may require sampling up to 6 hours post admission for safe ruleout. $^{21}$

Laboratory based assays and accelerated diagnostic pathways.

Clinical studies of POC testing can be divided into those evaluating clinical diagnostic performance and those assessing the impact of these tests on patient flow and cost economics. The early POC studies, including RATPAC and ASPECT, evaluated older multi-marker approaches incorporating creatine kinase, myoglobin, and troponin. ${ }^{22,23}$ These protocols enabled safe identification of low-risk patients who could be discharged early from hospital-based care. The subsequent introduction of lab-based troponin assays with higher analytical sensitivity and precision, enabled more accurate detection of 
small infarcts as well as faster diagnosis, and saw the interest in multi-marker POC platforms falter. However contemporary POC assay results incorporated into strategies with risk scores have been shown to be safe and accurate when compared with lab-based high-sensitivity assay strategies. For example, the Troponin-only Manchester Acute Coronary Syndromes (T-MACS) decision aid utilising POC CTnT results may enable $1 / 3^{\text {rd }}$ of ED patients to have ACS ruled-out within three hours. ${ }^{24}$ Additionally, the early measurement and detection of significant troponin elevation to rule-in MI using POC assays, including less sensitive systems has been shown. ${ }^{25}$ Overall, however, the efficiency of contemporary POC clinical strategies cannot compete with the optimised lab-based hs-cTn protocols.

As there are no guideline-recommended accelerated diagnostic pathways utilising either contemporary or high-sensitivity POC assays ${ }^{2,15}$ to consider the benefits, an understanding of the utilisation of lab-based hs-cTn assays is crucial. Very low hs-cTn concentrations at admission, defined as hs-cTn close to or below the LoD in patients presenting more than two hours after onset of symptoms, may rule-out a $\mathrm{MI}$ without the need for re-testing. ${ }^{3}$ The option to rule-out a $\mathrm{MI}$ using a single, very low hs-cTn concentration is particularly interesting for accelerating assessment and enabling discharge of low risk patients from busy EDs. ${ }^{26,27}$ Strong evidence supporting the safety and efficacy of instant and early rule-out protocols using lab-based assays exists (Table 2). ${ }^{28,29}$ Care is needed in utilisation of such strategies though, as some patients are not able to precisely state the onset of their symptoms or to recall the exact time of the last chest pain episode. The proportion of patients who qualify for the 0 -hour rule-out option is around $30 \%$ in a meta-analysis that included eleven cohorts with a total of 9,241 participants. ${ }^{29}$

For patients not meeting the criteria for single troponin testing, the interval between serial measurements should be long enough to overcome the troponin-blind period that is typically seen following the early hour(s) of a MI. ${ }^{3}$ Validated algorithms that allow for an earlier detection of a MI 
with re-testing using a high sensitivity assay after 1,2, or 3 hours instead of 6 to 9 hours that were recommended with less sensitive troponin assays. ${ }^{3}$ At this stage, the algorithms are used to predict either a low probability (rule-out) or a high probability (rule-in) of a diagnosis of MI on follow up and do not use the $99^{\text {th }}$ percentile upper limit of normal. ${ }^{3}$ They use lower thresholds and concentration changes optimised to rule-out MI with a sensitivity of $>99 \%$ or rule-in with a specificity of $>75 \%$. When diagnosis is uncertain, patients are classified to an intermediate risk zone and subsequent testing is recommended. high prevalence of chronic elevation of troponin.

\section{Accuracy of POC Hs-troponin}

Recent studies suggest that new POC hs-cTn assays are comparable to laboratory-based assays and that early assessment strategies (0-hour and 0-1-hour protocols) may also be achievable (Table 3).6,7 These studies have reported potential benefits though utilised stored, rather than whole, blood. $6,7,20$ These studies show promise in that early rule-out using single samples and serial sampling strategies may be able to safely manage emergency patients with suspected ACS. However, a criticism of all these studies is that they have been performed using stored serum or plasma in controlled 
environments. Although they demonstrate comparable diagnostic performance with laboratorybased assay they have not been performed using whole blood in the point of care ED environment. However, one recent study of a hs-cTn POC assay has compared results using both whole blood and plasma has shown results that are analytically equivalent. ${ }^{30}$ The theoretical health service benefits of rapid assessment strategies using POC hs-cTn assays described now require evaluation when implemented into clinical practice.

\section{Potential role of POC assays}

A key benefit of POC assays is the short turnaround time with most reporting less than 20 minutes from testing to results. ${ }^{6-9,} 19,20$ With the need for serial cTn testing, older POC cTn assays have shown conflicting results in terms of reduced ED length of stay and economic benefits, ${ }^{31,32,33}$ yet have been shown to improve the speed with which AMI patients are identified. ${ }^{34}$ Indeed the recent PROACT-4 trial, where POC troponin was tested in the ambulance setting, reported only modest time-savings (0.3 hour) from first medical contact to discharge from ED or admission. ${ }^{35}$ As no studies have reported the impact of utilisation of POC hs-cTn assays in actual patient care (due to the newness of this technology), our understanding of the effects of accelerated risk stratification on health systems is also derived from reports using lab-based assays. Patient risk stratification and management practices vary considerably between hospitals, countries, and continents. Adoption of accelerated assessment strategies has been shown to have significant benefits for health services internationally, including sites in Europe and Australia. ${ }^{4,26,27,36}$ Rates of major adverse cardiovascular events at 30days in low risk patients post adoption of strategies remain low $(<1 \%) \cdot{ }^{36}$ The effects of implementation of a 0-1 hour algorithm was evaluated by two registries reporting that more patients could be discharged, with shorter lengths of stay in the ED, and without an excess of resources for work-up compared to the 0-3 hour protocol. ${ }^{26,27}$ Notably, rates of coronary angiography and functional testing remained consistently low after implementation of the 0-1-hour protocol instead of the 0-3-hour protocol. A similar finding has been reported in the High STEACS 
147 and HiSTORIC trials. ${ }^{37,38}$ In contrast, the randomised RAPID-TnT study evaluating a 0-1- and 0-3-hour

148 protocol showed the use of invasive coronary investigation was increased among patients with

149 newly identified low-concentration troponin elevations. ${ }^{36}$

Although diagnostic protocols are getting faster and demonstrate additional benefits including safety

152 of discharge, reduction of the length of ED stay, and cost effectiveness, the global implementation

153 rate of high-sensitivity troponin assays is far behind expectations. A 2019 survey ${ }^{39}$ found that only $41 \%$

154 of hospitals worldwide use hs-cTn assays and <10\% implement a 0/1-hour or 0/2-hour protocol.

155 Possible reasons for this include infrastructural barriers that hinder embracing the benefits of shorter

156 turnaround times for results, which may be negated by access to high-sensitivity POC assays.

\section{The future of POC troponin assays}

159 Within the busy ED, opportunities to safely improve the efficiency of assessment of patients are

160 welcomed. POC analysis of key biomarkers enables clinicians to have results proximate to care,

161 assisting in diagnosis and disposition planning. With the advent of POC Hs-cTn assays, the potential

162 of a single analysis of cTn (0-hour only) with the ability to immediately rule-out an AMI for some patients needing evaluation for possible $\mathrm{Ml}$ is attractive, and may improve efficiency in assessment if this strategy is adopted into clinical care. ${ }^{3} \mathrm{~A}$ key dependency on the impact of POC devices is confidence that results are reliable and accurate, and that all pathology investigations that are required are available. Consideration of the entire process of assessment is paramount for effective

167 utilisation of POC testing. For example, without additional investigation results, such as haemoglobin, electrolytes and creatinine being readily available, POC Hs-cTn assays may not have a significant impact on ED efficiency. The literature to date illustrates that it is not the provision of rapid cTn results alone that is important but their inclusion within a clinical decision-making 
171 pathway. ${ }^{32}$ Widespread adoption of change also requires systematic clinical redesign of assessment pathways to achieve maximum impact. ${ }^{4}$

173 Currently, most patients with proximate symptoms of suspected ACS are referred to places where 174 definitive risk stratification can occur. Access to POC hs-cTn assays may change this, yet this would 175 be reliant on several key issues being addressed. These issues include the availability of POC hs-cTn, 176 a proven record of safety and accuracy in ruling out AMI on a single blood draw, and potentially that 177 samples are able to be performed using finger stick (rather than a technically more complex 178 venepuncture) to enable less skilled personnel to accurately test. If these issues are addressed, 179 primary care physicians (who in many places around the world currently perform and report ECGs) would also be able to assess and rule-out the need for patients at low risk of an MI being referred to local EDs. Such use of in the primary care setting may be highly beneficial to safely identify low risk patients due to the lower prevalence of ACS in this cohort. A similar strategy may be supported in cardiologists' rooms or outpatients where at-risk patients may be seen.

Correct identification of higher risk patients for NSTEMI in the pre-hospital setting may also prove valuable..$^{40}$ Variation in the in-hospital management of AMI patients occurs, correlating with the availability of cardiac procedures ${ }^{41}$ and patients with NSTEMIs or other acute cardiac conditions are

187 ideally managed with specialist cardiac care. The ability to identify patients suspected of having ACS early with elevated troponin values in the prehospital phase of care may support the correct disposition of patients and avoid the need for secondary transfer ${ }^{42}$ reducing burden on health care and ambulance services. The results of studies into pre-hospital use of POC assays currently underway are eagerly awaited, including those from the ARTICA ${ }^{43}$ and PRESTO ${ }^{44}$ trials.

\section{Conclusion}

193 The evolution of troponin assays continues, and POCT hs-cTn assays soon will become more widely 194 accessible. Evidence is required to ensure that emerging POCT hs-cTn assays meet both analytical 
195 and clinical needs, and robust redesign of models of care will be needed to maximise the potential

196 benefits. Randomised controlled trials incorporating POCT hs-cTn are required to identify the impact

197 on assessment of patients with suspected ACS in emergency, prehospital, and primary care settings. 


\section{References}

1. Anderson JL, Morrow DA. Acute myocardial infarction. N Engl J Med 2017;376(21):2053-64. doi: 10.1056/NEJMra1606915

2. Thygesen K, Alpert JS, Jaffe AS, et al. Fourth universal definition of myocardial infarction (2018). Circulation 2018;138(20):e618-e51. doi: 10.1161/CIR.0000000000000617 [published Online First: 2018/12/21]

3. Collet JP, Thiele H, Barbato E, et al. 2020 ESC Guidelines for the management of acute coronary syndromes in patients presenting without persistent ST-segment elevation. Eur Heart J 2021;42:1289-367.

4. Greenslade JH, Parsonage W, Foran L, et al. Widespread introduction of a high-sensitivity troponin assay: assessing the impact on patients and health services. J Clin Med 2020;9(6):1883. doi: 10.3390/jcm9061883 [published Online First: 2020/06/21]

5. Apple FS, Collinson PO. Analytical characteristics of high-sensitivity cardiac troponin assays. Clin Chem 2012;58(1):54-61. doi: 10.1373/clinchem.2011.165795.

6. Boeddinghaus J, Nestelberger T, Koechlin L, et al. Early diagnosis of myocardial infarction with point-of-care high-sensitivity cardiac troponin I. J Am Coll Cardiol 2020;75(10):1111-24. doi: 10.1016/j.jacc.2019.12.065 [published Online First: 2020/03/14]

7. Sorensen NA, Neumann JT, Ojeda F, et al. Diagnostic evaluation of high-sensitivity troponin I point-of-care assay. Clin Chem 2019;65(12):1592-601. doi: 10.1373/clinchem.2019.307405

8. Apple FS, Schulz K, Schmidt CW, et al. Determination of sex-specific 99th percentile upper reference limits for a point of care high sensitivity cardiac troponin I assay. Clin Chem Lab Med. 2021 May 24. doi: 10.1515/cclm-2021-0262. Online ahead of print. PMID: 34022125.

9. Venge $P$, van Lippen L, Blaschke $S$, et al. Equal clinical performance of a novel point-of-care cardiac troponin I (cTnI) assay with a commonly used high-sensitivity cTnl assay. Clin Chim Acta 2017;469:119-25. doi: 10.1016/j.cca.2017.03.023

10. Alpert JS, Thygesen K, Antman E, et al. Myocardial infarction redefined--a consensus document of The Joint European Society of Cardiology/American College of Cardiology Committee for the redefinition of myocardial infarction. J Am Coll Cardiol 2000;36(3):959-69. doi: 10.1016/s07351097(00)00804-4

11. Nomenclature and criteria for diagnosis of ischemic heart disease. Report of the Joint International Society and Federation of Cardiology/World Health Organization task force on standardization of clinical nomenclature. Circulation 1979;59(3):607-9. doi: 10.1161/01.cir.59.3.607

12. Thygesen K, Alpert JS, White HD, et al. Universal definition of myocardial infarction. Circulation 2007;116(22):2634-53. doi: 10.1161/CIRCULATIONAHA.107.187397

13. Wu AHB, Christenson RH, Greene DN, et al. Clinical laboratory practice recommendations for the use of cardiac troponin in acute coronary syndrome: expert opinion from the Academy of the American Association for Clinical Chemistry and the Task Force on Clinical Applications of Cardiac Bio-Markers of the International Federation of Clinical Chemistry and Laboratory Medicine. Clin Chem. 2018;64(4):645-55. doi: 10.1373/clinchem.2017.277186 
14. Eggers KM, Jernberg T, Lindahl B. Cardiac troponin elevation in patients without a specific diagnosis. J Am Coll Cardiol 2019;73(1):1-9. doi: 10.1016/j.jacc.2018.09.082

15. Diagnostics guidance [DG40]. Diagnostics Assessment Committee National Institute for Health and Care Excellence. High-sensitivity troponin tests for the early rule out of NSTEMI. NICE 2020 [published Online First: August 26, 2020]

16. IFCC Committee on Clinical Applications of Cardiac Bio-Markers (C-CB). High sensitivity cardiac troponin I and T assay analytical characteristics. 2020; https://www.ifcc.org/media/478592/highsensitivity-cardiac-troponin-i-and-t-assay-analytical-characteristics-designated-by-manufacturerv072020.pdf Accessed 31 July 2021

17. Apple FS, Murakami MM, Christenson RH, et al. Analytical performance of the i-STAT cardiac troponin I assay. Clin Chim Acta 2004;345(1-2):123-7. doi: 10.1016/j.cccn.2004.03.010

18. Zhang $\mathrm{R}$, Hong $\mathrm{Y}$, Shi J, et al. Analytical characterization and clinical performance evaluation of a new point-of-care testing system for high-sensitivity cardiac troponin I assay. Ann Clin Biochem 2021 July 8:45632211027604. doi: 10.1177/00045632211027604. Epub ahead of print. PMID: 34120481.

19. Braga F, Aloisio E, Panzeri A, et al. Analytical validation of a highly sensitive point-of-care system for cardiac troponin I determination. Clin Chem Lab Med 2019;58(1):138-45.

20. Pickering JW, Young JM, George PM, et al. Validity of a novel point-of-care troponin assay for single-test rule-out of acute myocardial infarction. JAMA Cardiol 2018;3(11):1108-12. doi: 10.1001/jamacardio.2018.3368 [published Online First: 2018/10/23]

21. Suh D, Keller DI, Hof D, et al. Rule-out of non-ST elevation myocardial infarction by five point of care cardiac troponin assays according to the $0 \mathrm{~h} / 3 \mathrm{~h}$ algorithm of the European Society of Cardiology. Clin Chem Lab Med 2018;56(4):649-57. doi: 10.1515/cclm-2017-0486

22. Than M, Cullen L, Reid CM, et al. A 2-h diagnostic protocol to assess patients with chest pain symptoms in the Asia-Pacific region (ASPECT): a prospective observational validation. Lancet 2011;377(9771):1077-84.

23. Goodacre SW, Bradburn M, Cross E, et al. The randomised assessment of treatment using panel assay of cardiac markers (RATPAC) trial: a randomised controlled trial of point-of-care cardiac markers in the emergency department. Heart 2011;97(3):190-96.

24. Body R, Almashali M, Morris N, et al. Diagnostic accuracy of the T-MACS decision aid with a contemporary point-of-care troponin assay. Heart 2019;105(10):768-74.

25. Rasmussen MB, Stengaard C, Sorensen JT, et al. Predictive value of routine point-of-care cardiac troponin $\mathrm{T}$ measurement for prehospital diagnosis and risk-stratification in patients with suspected acute myocardial infarction. Eur Heart J Acute Cardiovasc Care 2019;8(4):299-308. doi:

$10.1177 / 2048872617745893$

26. Stoyanov KM, Hund H, Biener M, et al. RAPID-CPU: a prospective study on implementation of the ESC 0/1-hour algorithm and safety of discharge after rule-out of myocardial infarction. Eur Heart J Acute Cardiovasc Care 2020;9(1):39-51. doi: 10.1177/2048872619861911 
27. Twerenbold R, Costabel JP, Nestelberger T, et al. Outcome of applying the ESC 0/1-hour algorithm in patients with suspected myocardial infarction. J Am Coll Cardiol 2019;74(4):483-94. doi: 10.1016/j.jacc.2019.05.046

28. Chiang $\mathrm{CH}$, Chiang $\mathrm{CH}$, Lee $\mathrm{GH}$, et al. Safety and efficacy of the European Society of Cardiology 0/1-hour algorithm for diagnosis of myocardial infarction: systematic review and meta-analysis. Heart 2020;106(13):985-91. doi: 10.1136/heartjnl-2019-316343

29. Pickering JW, Than MP, Cullen L, et al. Rapid rule-out of acute myocardial infarction with a single high-sensitivity cardiac troponin $\mathrm{T}$ measurement below the limit of detection: a collaborative metaanalysis. Ann Intern Med 2017;166(10):715-24. doi: 10.7326/M16-2562

30. Gopi V, Milles B, Spanuth E, et al. Comparison of the analytical performance of the PATHFAST high sensitivity cardiac troponin I using fresh whole blood vs. fresh plasma samples. Clin Chem Lab Med. 2021 June 4. doi: 10.1515/cclm-2021-0354. Epub ahead of print. PMID: 34087961

31. Apple FS, Chung AY, Kogut ME, et al. Decreased patient charges following implementation of point-of-care cardiac troponin monitoring in acute coronary syndrome patients in a community hospital cardiology unit. Clin Chim Acta 2006;370(1-2):191-5. doi: 10.1016/j.cca.2006.02.011

32. Bradburn M, Goodacre SW, Fitzgerald P, et al. Interhospital variation in the RATPAC trial (Randomised Assessment of Treatment using Panel Assay of Cardiac markers). Emerg Med J 2012;29(3):233-8. doi: 10.1136/emj.2010.108522

33. Carlton E, Campbell S, Ingram J, et al. Randomised controlled trial of the Limit of Detection of Troponin and ECG Discharge (LoDED) strategy versus usual care in adult patients with chest pain attending the emergency department: study protocol. BMJ Open 2018;8(10):e025339. doi: 10.1136/bmjopen-2018-025339

34. Goyder C, Tan PS, Verbakel J, et al. Impact of point-of-care panel tests in ambulatory care: a systematic review and meta-analysis. BMJ Open 2020;10(2):e032132. doi: 10.1136/bmjopen-2019032132.

35. Ezekowitz JA, Welsh RC, Weiss D, et al. Providing Rapid Out of Hospital Acute Cardiovascular Treatment 4 (PROACT-4). J Am Heart Assoc. 2015;4(12):e002859. Published 2015 Dec 1. doi: 10.1161/JAHA.115.002859.

36. Chew DP, Lambrakis K, Blyth A, et al. A randomized trial of a 1-hour troponin T protocol in suspected acute coronary syndromes: the Rapid Assessment of Possible Acute Coronary Syndrome in the Emergency Department with High-Sensitivity Troponin T Study (RAPID-TnT). Circulation 2019;140(19):1543-56. doi: 10.1161/circulationaha.119.042891

37. Bularga A, Lee KK, Stewart S, et al. High-sensitivity troponin and the application of risk stratification thresholds in patients with suspected acute coronary syndrome. Circulation 2019;140(19):1557-68. doi: 10.1161/CIRCULATIONAHA.119.042866 [published Online First: 2019/09/03]

38. Shah ASV, Anand A, Strachan FE, et al. High-sensitivity troponin in the evaluation of patients with suspected acute coronary syndrome: a stepped-wedge, cluster-randomised controlled trial. Lancet 2018;392(10151):919-28. doi: 10.1016/S0140-6736(18)31923-8 [published Online First: 2018/09/02] 
39. Anand A, Shah ASV, Beshiri A, et al. Global adoption of high-sensitivity cardiac troponins and the universal definition of myocardial infarction. Clin Chem 2019;65(3):484-89. doi:

10.1373/clinchem.2018.298059

40. Alghamdi A, Alotaibi A, Alharbi M, et al. Diagnostic performance of prehospital point-of-care troponin tests to rule out acute myocardial infarction: a systematic review. Prehosp Disaster Med. 2020 Oct;35(5):567-573. doi: 10.1017/S1049023X20000850. Epub 2020 Jul 9. PMID: 32641173.

41. Pilote L, Califf RM, Sapp S, et al. Regional variation across the United States in the management of acute myocardial infarction. GUSTO-1 Investigators. Global Utilization of Streptokinase and Tissue Plasminogen Activator for Occluded Coronary Arteries. N Engl J Med 1995;333(9):565-72. doi: 10.1056/NEJM199508313330907.

42. Stopyra JP, Snavely AC, Scheidler JF, et al. Point-of-care troponin testing during ambulance transport to detect acute myocardial infarction. Prehosp Emerg Care 2020;24(6):751-59. doi: 10.1080/10903127.2020.1721740 [published Online First: 2020/01/28].

43. Aarts GWA, Camaro C, van Geuns R, et al Acute rule-out of non-ST-segment elevation acute coronary syndrome in the (pre)hospital setting by HEART score assessment and a single point-of-care troponin: rationale and design of the ARTICA randomised trial. BMJ Open 2020;10:e034403. doi: 10.1136/bmjopen-2019-034403.

44. Alghamdi A, Cook E, Carlton E, et al. Pre-hospital evaluation of sensitive troponin (PRESTO) study: multicentre prospective diagnostic accuracy study protocol. BMJ Open 2019;9:e032834. doi:

10.1136/bmjopen-2019-032834. 
Table 1. Performance characteristics of POCT troponin assays. ${ }^{8,16,18}$

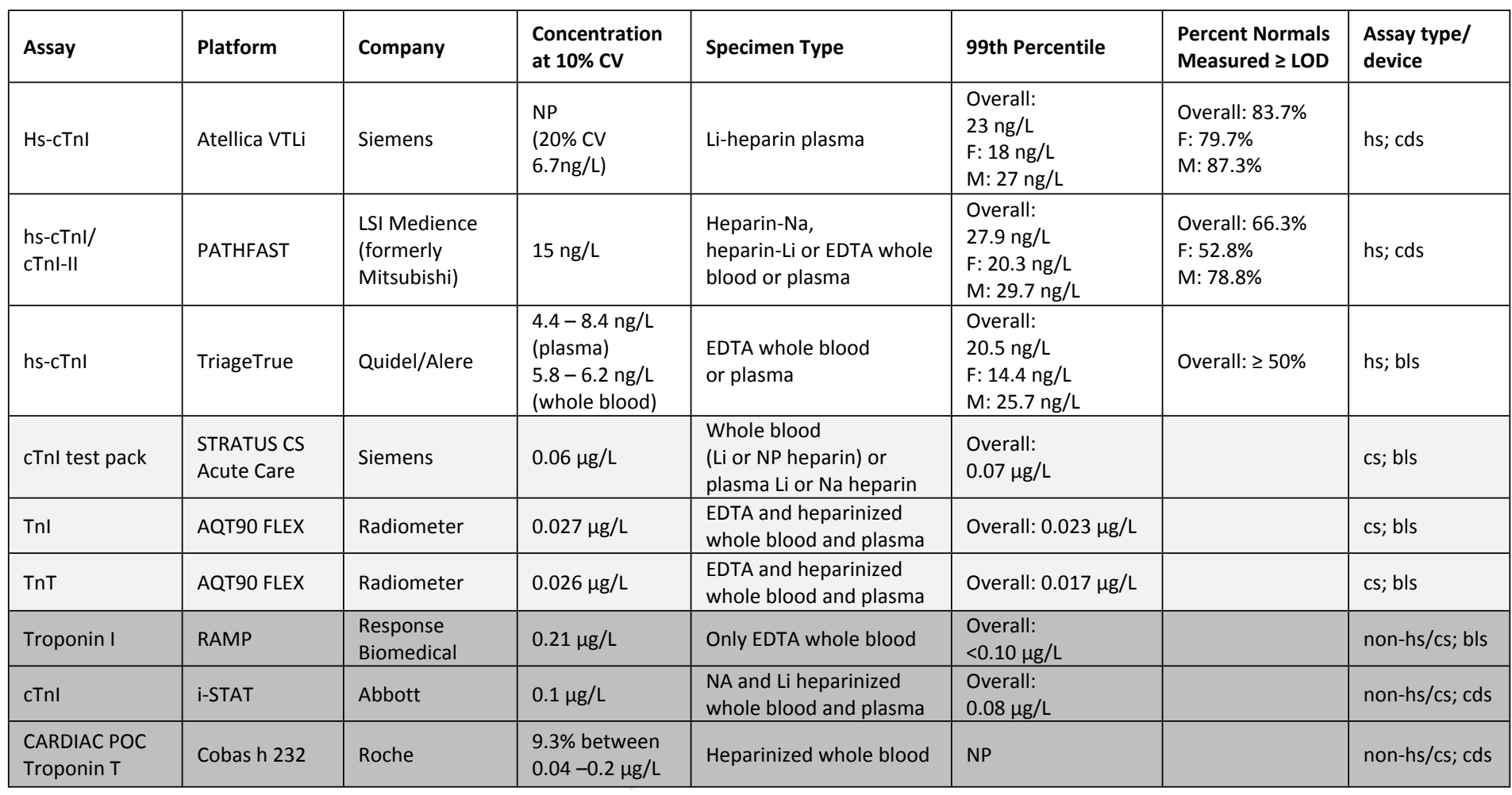

hs-cTnl: high-sensitivity cardiac troponin I; Tnl: troponin I; TnT: troponin T; Na: sodium; Li: lithium; EDTA: hs: high sensitivity; cs: contemporary sensitivity; cds: compact desktop systems; bls: bedside use NP: Not provided

Adapted from the International Federation of Clinical Chemistry and Laboratory Medicine - Clinical Applications of Cardiac Bio-Markers Updated tables. https://www.ifcc.org/media/477653/point-ofcare-cardiac-troponin-i-and-t-assay-analytical-characteristics-designated-by-manufacturerv012019.pdf 
Table 2. Overview on the performance of fast rule-out strategies based on single and serial blood draw at 0 hour/1 houra

\begin{tabular}{|c|c|c|c|c|c|c|c|c|c|c|}
\hline Study & $\begin{array}{c}\text { Test } \\
\text { Principle }\end{array}$ & Company & $\begin{array}{c}\text { Meta- } \\
\text { analysis } \\
\text { Cohorts }\end{array}$ & Troponin (ng/L) & $\begin{array}{l}\text { Sensitivity } \\
\text { (Pooled) }\end{array}$ & $\begin{array}{c}\text { NPV } \\
\text { (Pooled) }\end{array}$ & $\begin{array}{l}\text { Proportion } \\
\text { Eligible for } \\
\text { Rule-Out }\end{array}$ & \multicolumn{3}{|c|}{$\begin{array}{c}\text { Event Rate } \\
\text { After Rule-Out }\end{array}$} \\
\hline & & & & & & & & MACE & Death & $\mathrm{MI}$ \\
\hline \multicolumn{11}{|c|}{ 0-Hour Rule-Out: Single hs-cTNT < LOD (SMS) } \\
\hline $\begin{array}{l}\text { Pickering, } \\
\text { et al. }{ }^{29}\end{array}$ & hs-cTnT & & $\begin{array}{c}11 \\
\text { cohorts } \\
9,241 \\
\text { patients }\end{array}$ & $\begin{array}{c}<\mathrm{LOD} \\
(<5 \mathrm{ng} / \mathrm{L})\end{array}$ & $\begin{array}{c}98.7 \% \\
(96.6-99.5)\end{array}$ & $\begin{array}{c}99.3 \% \\
(97.3-99.8)\end{array}$ & $30.60 \%$ & $\begin{array}{c}21 / \\
8,059\end{array}$ & $1.30 \%$ & $\begin{array}{c}14 / \\
8,059\end{array}$ \\
\hline \multicolumn{11}{|c|}{ ESC $0 / 1$ Hour: Either very low 0 hour < LOD or low hs-cTNT and small $\delta$ between $0 / 1$ hour } \\
\hline \multirow{3}{*}{$\begin{array}{l}\text { Chiang, } \\
\text { et al. }{ }^{28} \\
15 \text { cohorts: } \\
11,014 \\
\text { patients }\end{array}$} & hs-cTnl & Abbott & 4 cohorts & $\begin{array}{c}\text { Either very low } \\
0 \text { hour }(<2 \mathrm{ng} / \mathrm{L}) \text {, } \\
\text { or low hs-cTnl } \\
(<5 \mathrm{ng} / \mathrm{L}) \text { and small } \\
\delta(<2 \mathrm{ng} / \mathrm{L}) \\
\text { between } 0-1 \text { hour }\end{array}$ & $\begin{array}{c}98.1 \% \\
(94.6 \text { to } 99.3)\end{array}$ & $\begin{array}{c}99 \% \\
(96.0 \text { to } \\
100)\end{array}$ & $50.00 \%$ & NA & $0.10 \%$ & NA \\
\hline & hs-cTnl & Siemens & 4 cohorts & $\begin{array}{c}\text { Either very low } \\
0 \text { hour }(<0.5 \mathrm{ng} / \mathrm{L}) \text {, } \\
\text { or low hs-cTnl }(<5 \\
\mathrm{ng} / \mathrm{L}) \text { and small } \delta \\
(<2 \mathrm{ng} / \mathrm{L}) \text { between } \\
0-1 \text { hour }\end{array}$ & $\begin{array}{c}98.7 \% \\
(97.3 \text { to } 99.3)\end{array}$ & $\begin{array}{c}100 \% \\
\text { (99 to } 100)\end{array}$ & $51.00 \%$ & NA & $0.10 \%$ & NA \\
\hline & hs-cTnT & Roche & $\begin{array}{c}7 \text { cohorts } \\
7,744 \\
\text { patients }\end{array}$ & $\begin{array}{c}\text { Either very low } \\
0 \text { hour (<5ng/L), } \\
\text { or low hs-cTnT } \\
(<12 \mathrm{ng} / \mathrm{L}) \text { and } \\
\text { small } \delta(<3 \mathrm{ng} / \mathrm{L}) \\
\text { between } 0-1 \text { hour }\end{array}$ & $\begin{array}{c}98.4 \% \\
(95.1-99.5)\end{array}$ & $\begin{array}{c}99.6 \% \\
(99.0-99.9)\end{array}$ & $55.00 \%$ & NA & $0.10 \%$ & NA \\
\hline
\end{tabular}

NPV: negative predictive value; LOD: limit of detection; SMS: single marker strategy; ESC: European Society of Cardiology; MACE: major adverse cardiac events; MI: myocardial infarction 
Table 3. Results from diagnostic accuracy studies of POCT hs-cTn assays at presentation for the diagnosis of AMI

\begin{tabular}{|c|c|c|c|c|c|}
\hline POC assay & $\begin{array}{l}\text { AUC } \\
\text { (95\%CI) }\end{array}$ & $\begin{array}{l}\text { Comparator } \\
\text { assay }\end{array}$ & $\begin{array}{l}\text { AUC } \\
\text { (95\%Cl) }\end{array}$ & Patients & AMI rate \\
\hline $\begin{array}{l}\text { PATHFAST } \\
\text { POC hs-cTnI }{ }^{7} \\
\text { (plasma) }\end{array}$ & $\begin{array}{l}0.91 \\
(0.89-0.93)\end{array}$ & $\begin{array}{l}\text { cTnl-Architect } \\
\text { (fresh serum } \\
\text { or plasma) }\end{array}$ & $\begin{array}{l}0.90 \\
(0.87-0.92)\end{array}$ & 1279 & $134(20 \%)$ \\
\hline $\begin{array}{l}\text { i-STAT Tnl- } \\
\mathrm{Nx}^{20^{*}} \\
\text { (plasma) }\end{array}$ & $\begin{array}{l}0.97 \\
(0.96-0.99)\end{array}$ & $\begin{array}{l}\text { cTnl-Architect } \\
\text { (plasma) }\end{array}$ & $\begin{array}{l}0.97 \\
(0.95-0.99)\end{array}$ & 354 & $57(16 \%)$ \\
\hline \multirow[t]{2}{*}{$\begin{array}{l}\text { Minicare POC } \\
\text { hs-cTnl }^{9} \\
\text { (Whole blood) }\end{array}$} & $\begin{array}{l}0.88 \\
(0.83-0.94)\end{array}$ & $\begin{array}{l}\text { cTnl-Architect } \\
\text { (serum or } \\
\text { plasma) }\end{array}$ & $\begin{array}{l}0.91 \\
(0.87-0.95)\end{array}$ & \multirow[t]{2}{*}{450} & \multirow[t]{2}{*}{$72(16 \%)$} \\
\hline & & $\begin{array}{l}\text { I-Stat POC } \\
\text { cTnl }\end{array}$ & $\begin{array}{l}0.88 \\
(0.82-0.94)\end{array}$ & & \\
\hline \multirow[t]{2}{*}{$\begin{array}{l}\text { Triage True } \\
\text { POC hs-cTnl } \\
\text { (plasma) }\end{array}$} & $\begin{array}{l}0.95 \\
(0.93-0.96)\end{array}$ & $\begin{array}{l}\text { cTnT Elecsys } \\
\text { (serum or } \\
\text { plasma) }\end{array}$ & $\begin{array}{l}0.94 \\
(0.93-0.96)\end{array}$ & \multirow[t]{2}{*}{1261} & \multirow[t]{2}{*}{$178(14 \%)$} \\
\hline & & $\begin{array}{l}\text { cTnl-Architect } \\
\text { (serum or } \\
\text { plasma) }\end{array}$ & $\begin{array}{l}0.92 \\
(0.90-0.93)\end{array}$ & & \\
\hline
\end{tabular}

*Note - analytical studies of this assay are pending. 